\title{
Bilateral Pretibial Edema Associated with Paliperidone Palmitate Long-acting Injectable: A Case Report
}

\author{
Erdinc Cicek ${ }^{1}$, Ismet Esra Cicek ${ }^{2}$, Faruk Uguz ${ }^{3}$ \\ ${ }^{1}$ Department of Psychiatry, Çumra State Hospital, ${ }^{2}$ Department of Psychiatry, Research and Training Hospital, ${ }^{3}$ Department of Psychiatry, Meram \\ Faculty of Medicine, University of Necmettin Erbakan, Konya, Turkey
}

\begin{abstract}
Peripheral edema is observed as an adverse effect of the usage of antipsychotics in the literature. This case report describes a 36-year-old female patient with the diagnosis of paranoid schizophrenia who presented with pretibial edema following initiation of long-acting injectable paliperidone palmitate. Pretibial edema developed within the second week of treatment and completely disappeared after its discontinuation.
\end{abstract}

KEY WORDS: Edema; Long-acting injectable; Paliperidone palmitate.

\section{INTRODUCTION}

Paliperidone palmitate, a long acting injectable (LAI) antipsychotic, is the palmitate ester of paliperidone and is widely used in patients with schizophrenia. ${ }^{1)}$ As with other antipsychotics, the mechanism of action of paliperidone is unclear. ${ }^{2,3)}$ The drug primarily acts as an antagonist of the dopamine D2 and serotonin-2A (5HT2A) receptors. Paliperidone also acts as an antagonist of $\alpha-1$ and $\alpha-2$ adrenergic receptors and histamine $\mathrm{H} 1$ receptors. ${ }^{1,4)}$ Paliperidone palmitate LAI provides continuous medication with a convenient dosing interval, aimed at enhancing treatment adherence for non-compliant patients with psychotic disorders. ${ }^{5)}$

Peripheral edema has been reported with atypical antipsychotics, such as olanzapine, risperidone, ziprasidone, quetiapine, amisulpride, ziprasidone and risperidone LAI. ${ }^{6-11)}$ Although there is only one published case report of peripheral edema related to paliperidone, to our knowledge, there is no case report in the published literature on peripheral edema associated with paliperidone palmitate LAI. ${ }^{12)}$ Herein, we present the case of a patient who developed pretibial edema after paliperidone palmitate LAI treatment.

\footnotetext{
Received: April 1, 2016/Revised: May 6, 2016

Accepted: May 11, 2016

Address for correspondence: Erdinc Cicek, MD

Department of Psychiatry, Çumra State Hospital, Izzet Bey Mah.

Gazi Cd. Cumra, Konya, Turkey

Tel: +90-332-4471027, Fax: +90-332-4475500

E-mail: erdinccicek@yahoo.com.tr
}

\section{CASE}

A 36-year-old female unmarried unemployed female patient who lived with her family was diagnosed with paranoid schizophrenia approximately 8 years prior. She had previously received multiple antipsychotics such as haloperidol, olanzapine, risperidone, amisulprid, and quetiapine. At the time of this study, the patient had used paliperidone at $6 \mathrm{mg}$ /day for 3 months. No relevant adverse side effects were noted during paliperidone treatment. The patient was brought to our outpatient clinic by her family because of worsening delusions, hallucinations and poor treatment adherence. The patient had a history of frequent relapse on oral medication due to non-compliance. Because of this poor history of compliance, paliperidone oral tablet was discontinued and the patient was initiated with paliperidone palmitate LAI $150 \mathrm{mg}$ on day 1 and 100 $\mathrm{mg}$ on day 8 . Following a month's usage of paliperidone palmitate LAI $100 \mathrm{mg}$, the patient presented with bilateral pretibial $2+$ pitting edema. Pretibial edema first occurred at the second week of treatment and then continued to increase gradually. There was no ulceration, erythema, discoloration of the skin, or pain accompanying the edema. The patient therefore consulted with cardiology, internal medicine and nephrology clinics. Complete blood count, thyroid stimulating hormone, vitamin B12, albumin, liver function tests (aspartate aminotransferase, alanine transaminase, gamma-glutamyl transpeptidase, albumin), renal function tests (urea, creatinine), serum electrolytes

(c) This is an Open-Access article distributed under the terms of the Creative Commons Attribution Non-Commercial License (http://creativecommons.org/licenses/by-nc/4.0) which permits unrestricted non-commercial use, distribution, and reproduction in any medium, provided the original work is properly cited. 
and rheumatological tests were performed. The results were found to be within normal limits and the patient had no physical problems. The patient did not use any other medication during this time of treatment. The pretibial edema in this case scored 6 on the Naranjo causality scale, suggesting that the adverse effect probably occurred as a result of paliperidone palmitate LAI. ${ }^{13)}$ Treatment with paliperidone palmitate LAI was replaced with aripiprazole. The pretibial edema was seen to decrease on the 20th day follow-up. By the end of the second month, the edema had completely resolved without any further intervention.

\section{DISCUSSION}

To the best of our knowledge, this is the first report of pretibial edema accompanying pharmacotherapy with paliperidone palmitate LAI. In the literature, there are reported peripheral edema cases associated with antipsychotics. ${ }^{6,8,10)}$ Paliperidone is the major active metabolite of risperidone and is available as both extended release oral tablet and long- acting injectable suspension for intramuscular use. ${ }^{4)}$

There is only one published case report of peripheral edema related to paliperidone. Chen et al $^{12)}$ described the development of edema in the dorsal side of the patient's feet 2 weeks after the initiation of treatment with $9 \mathrm{mg}$ paliperidone, which disappeared completely after the discontinuation of paliperidone. Again, only one report exists in the literature showing the occurrence of periorbital edema within 14 days of treatment of schizophrenia with $50 \mathrm{mg}$ risperidone LAI. ${ }^{7)}$ There are several reports on risperidone induced edema either with risperidone alone or in combination with other drugs such as citalopram, sodium valproate and/or benzodiazepines. ${ }^{6,14,15)}$

The mechanism of action of antipsychotics that lead to the development of peripheral edema is currently unknown. Like risperidone, paliperidone primarily acts by blocking 5HT2, D2, $\alpha-1, \alpha-2$ and H1 receptors. ${ }^{1)}$ These antipsychotics may cause edema by blocking $\alpha-1$ receptors, resulting in vasodilation, decreased vascular resistance and an increase in hydrostatic pressure in the capillaries. ${ }^{16)}$ Secondly, 5HT2 receptor blockade can increase cyclic adenosine monophosphate concentration, which relaxes vascular smooth muscle and results in edema. ${ }^{11)}$ Thirdly, M1, H1 and 5HT2 receptors blockade can prevent the physiological increase of IP3, reducing smooth muscle contractility and resulting in vasodilation and edema. ${ }^{17)}$

Chen et al. ${ }^{12)}$ reported that paliperidone and risperidone share common pathogenic pathways that may induce edema. The authors hypothesized that the excipients of paliperidone such as titanium dioxide, propylene glycol and ionic compounds containing sodium can cause the edematous events. Pelizza ${ }^{7)}$ reported that the peripheral edema associated with risperidone LAI may have resulted from the nontherapeutic components of risperidone LAI, such as a combination of the polylactide-co-glycolide extended release microspheres and the diluent for parenteral use.

Interestingly, in our patient, pretibial edema was observed during treatment with paliperidone LAI but not during treatment with oral paliperidone. This may be explained by the cumulative period of exposure of the patient to paliperidone with different pharmacokinetic characteristics such as absorption, distribution and metabolism of the medication, depending on the route of administration of the drug. Additionally pretibial edema may be associated with the excipients of paliperidone LAI such as polysorbate 20, polyethylene glycol 4000, citric acid monohydrate, disodium hydrogen phosphate anhydrous, sodium dihydrogen phosphate monohydrate and sodium hydroxide. Furthermore, as shown in the current case, the development of edema may take up to two months.

In conclusion, the present case suggests that even if peripheral edema does not develop with oral paliperidone, paliperidone LAI may cause this side effect. More extensive and comprehensive studies are required to better assess the incidence and mechanism of this adverse effect of long-acting injection antipsychotics.

\section{REFERENCES}

1. Gilday E, Nasrallah HA. Clinical pharmacology of paliperidone palmitate a parenteral long-acting formulation for the treatment of schizophrenia. Rev Recent Clin Trials 2012;7: 2-9.

2. Taylor D. Psychopharmacology and adverse effects of antipsychotic long-acting injections: a review. Br J Psychiatry Suppl 2009;52:S13-S19.

3. Gopal S, Gassmann-Mayer C, Palumbo J, Samtani MN, Shiwach R, Alphs L. Practical guidance for dosing and switching paliperidone palmitate treatment in patients with schizophrenia. Curr Med Res Opin 2010;26:377-387.

4. Chwieduk CM, Keating GM. Paliperidone extended release: a review of its use in the management of schizophrenia. Drugs 2010;70:1295-1317.

5. Samtani MN, Gopal S, Gassmann-Mayer C, Alphs L, Palumbo JM. Dosing and switching strategies for paliperidone palmitate: based on population pharmacokinetic modelling and clinical trial data. CNS Drugs 2011;25:829-845.

6. Yang HN, Cheng YM. Peripheral edema associated with risperidone oral solution: a case report and a review of the literature. J Clin Psychopharmacol 2012;32:128-130.

7. Pelizza L. Long-acting risperidone-induced periorbital edema. $J$ Clin Psychopharmacol 2008;28:709-710.

8. Mathan K, Muthukrishnan V, Menon V. Olanzapine-induced tender pitting pre-tibial edema. J Pharmacol Pharmacother 
2015;6:114-115.

9. O'Connor N, Andronikashvili L, Adra A. Quetiapine causing peripheral oedema. Australas Psychiatry 2009;17:511-512.

10. Chen CK, Chou YH. Amisulpride-associated pedal edema. Eur Psychiatry 2004;19:454-455.

11. $\mathrm{Ku} \mathrm{HL}, \mathrm{Su} \mathrm{TP}$, Chou YH. Ziprasidone-associated pedal edema in the treatment of schizophrenia. Prog Neuropsychopharmacol Biol Psychiatry 2006;30:963-964.

12. Chen HJ, Lin ST, Hsu HC, Cheng KD, Tsang HY. Paliperidone-related peripheral edema: a case report and review of the literature. J Clin Psychopharmacol 2014;34: 269-271.

13. Naranjo CA, Busto U, Sellers EM, Sandor P, Ruiz I, Roberts $\mathrm{EA}$, et al. A method for estimating the probability of adverse drug reactions. Clin Pharmacol Ther 1981;30:239-245.

14. Sanders RD, Lehrer DS. Edema associated with addition of risperidone to valproate treatment. $J$ Clin Psychiatry 1998;59:689-690.

15. Hosseini SH, Ahmadi A. Peripheral edema occurring during treatment with risperidone combined with citalopram. Case Rep Med 2012;2012:540732.

16. Feroz-Nainar C, Selvaraj P, Roy M. Risperidone induced oedema in a child with learning disability and autism. Autism 2006;10:308-310.

17. Ng B, Postlethwaite A, Rollnik J. Peripheral oedema in patients taking olanzapine. Int Clin Psychopharmacol 2003; 18:57-59. 